Revista Eletrônica Geografar, Curitiba, v. 2, Resumos do VI Seminário Interno de Pós-Graduação em Geografia, p. 70-70. Junho/2007

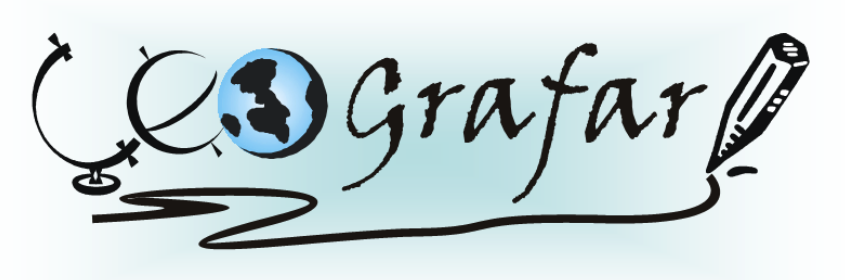

Revista Eletrônica do Programa de Pós-Graduação em Geografia - UFPR

\title{
FATORES SÓCIO-ECONÔMICOS E AMBIENTAIS E SUA INFLUÊNCIA NAS DOENÇAS RESPIRATÓRIAS - CURITIBA/PR
}

\section{SONIA MARIA CIPRIANO BAKONYI ${ }^{1}$}

A crescente concentração populacional no meio urbano se faz acompanhar pela deterioração da qualidade de vida, nas grandes cidades dos paises em desenvolvimento. No que diz respeito ao caso brasileiro "a dinâmica de urbanização associada a uma crise na gestão pública têm como resultado uma explicitação de carências sociais e dos serviços públicos e uma dificuldade concreta de gestão administrativa" (FERREIRA, 1997) o que sob a ótica da saúde repercute no agravamento de patologias respiratórias. O Sistema de Saúde brasileiro trabalha hoje com populações adstritas em suas unidades de saúde, ou seja, uma forma de se conhecer os problemas sociais e de saúde da comunidade sob sua responsabilidade, demonstrando a relevância do espaço e do território para a saúde pública. Nesse contexto esta pesquisa se propõe investigar a influência dos fatores sócioeconômicos e ambientais e seu impacto na saúde das populações, no que se refere a morbimortalidade por doenças respiratórias. Analisar-se-á o Município de Curitiba e o aglomerado urbano por se entender que a conurbação tenha influência no agravamento das doenças respiratórias. Pretende-se apontar indicadores ambientais e sócio-econômicos como parâmetros de saúde pública em termos de Doenças Respiratórias à luz da Geografia da Saúde e da Epidemiologia. As doenças serão correlacionadas com as variáveis atmosféricas, a industrialização, a frota automobilística, a renda per capta e o grau de escolaridade a partir de estudos de séries temporais e de modelos de regressão linear os quais possibilitam descrever a relação entre uma variável explanatória (independente) e uma variável resposta (dependente). Investiga-se ainda a questão do Gênero em Crianças e Idosos com o intuito de identificar os indivíduos mais vulneráveis. Resultados preliminares apontam as crianças do sexo masculino como as mais afetadas nos onze anos da série analisada, fato este que não ocorreu com os idosos.

Palavras-Chave: Geografia da Saúde, Indicador de Saúde, Doenças Respiratórias.

${ }^{1}$ Doutoranda em Geografia - UFPR - email: sbakonyi@onda.com.br Orientadora: INÊS MORESCO-DANNI OLIVEIRA 